\title{
Pituitary Disease in Pregnancy: Special Aspects of Diagnosis and Treatment?
}

\author{
Hypophysenerkrankungen in der Schwangerschaft: \\ Besonderheiten in der Diagnostik und Therapie?
}

\section{(ㄷ) (i) $($ 오 $\Theta$}

\section{Authors}

Stephan Petersenn ${ }^{1}$, Mirjam Christ-Crain ${ }^{2}$, Michael Droste ${ }^{3}$, Reinhard Finke ${ }^{4}$, Jörg Flitsch ${ }^{5}$, llonka Kreitschmann-Andermahr ${ }^{6}$, Anton Luger ${ }^{7}$, Jochen Schopohl ${ }^{8}$, Günter Stalla ${ }^{8,9}$

Affiliations

1 ENDOC Praxis für Endokrinologie, Andrologie und medikamentöse Tumortherapie, Hamburg, Germany

2 Endokrinologie, Diabetologie \& Metabolismus. Universitätsspital Basel, Basel, Switzerland

3 Endokrinologie, Diabetologie, Hormonanalytik. MEDICOVER MVZ, Oldenburg, Germany

4 Praxis an der Kaisereiche (üBAG), Berlin-Friedenau, Germany

5 Klinik und Poliklinik für Neurochirurgie, Kopfund Neurozentrum, Universitätsklinikum HamburgEppendorf, Hamburg, Germany

6 Neurochirurgische Klinik, Universitätsklinikum Essen, Universität Duisburg-Essen, Essen, Germany

7 Universitätsklinik für Innere Medizin III, Klinische Abteilung für Endokrinologie \& Stoffwechsel, Medizinische Universität Wien, Wien, Austria

8 Medizinische Klinik und Poliklinik IV, Klinikum der Universität München, München, Germany

9 Medicover Neuroendokrinologie, München, Germany

Key words

pituitary disease, pituitary tumor, pregnancy, fertility, diabetes insipidus

Schlüsselwörter

Hypophysenerkrankungen, Hypophysentumor,

Schwangerschaft, Fertilität, Diabetes insipidus

received 9.8.2018

revised 14.10.2018

accepted $\quad 10.11 .2018$

Bibliography

DOI https://doi.org/10.1055/a-0794-7587

Published online 6.3.2019 | Geburtsh Frauenheilk 2019; 79: 365-374 @ Georg Thieme Verlag KG Stuttgart - New York | ISSN 0016-5751
Correspondence

Prof. Dr. med. Stephan Petersenn

ENDOC Praxis für Endokrinologie, Andrologie

und medikamentöse Tumortherapie

Erik-Blumenfeld-Platz 27A, 22587 Hamburg, Germany

stephan.petersenn@endoc-med.de

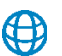
Deutsche Version unter: https://doi.org/10.1055/a-0794-7587

\section{ABSTRACT}

The diagnosis and treatment of pituitary disease in pregnancy represents a special clinical challenge. Not least because there is very little data on the treatment of pregnant patients with pituitary disorders. A selective search of the literature was carried out with the aim of compiling evidence about the diagnosis and treatment of pituitary disease in pregnancy. The search covered the databases PubMed/MEDLINE including PubMed Central and also used the Livivo (ZB MED) search engine. Recent studies were evaluated for recommendations about the care of pregnant patients with hormone-inactive and hormone-active pituitary adenomas (prolactinoma, acromegaly and Cushing's disease), pituitary insufficiency, pituitary apoplexy and hypophysitis. The most well-established forms of treatment are for prolactinoma, due to the incidence of this disease and its impact on fertility. When pregnancy has been confirmed, prolactinoma treatment with dopamine agonists should be paused. Although microprolactinomas rarely increase significantly in size after the administration of dopamine agonists is discontinued, symptomatic tumor growth of macroprolactinomas can occur. In such cases, treatment with dopamine agonists can be resumed. If the primary tumor is large and the risk that it will continue to grow is high, it may be necessary to continue medical treatment from the start of pregnancy. If one of the partners has a pituitary disorder, it is often still possible for many couples to achieve their wish of having children if they receive medical support to plan and the pregnancy is carefully monitored. Given the complexity of pituitary disease, pregnant patients with pituitary disorders 
should be cared for and treated by a multidisciplinary team in centers specializing in the diagnosis and treatment of pituitary disease.

\section{ZUSAMMENFASSUNG}

Diagnose und Therapie von Hypophysenerkrankungen stellen in der Schwangerschaft eine besondere klinische Herausforderung dar. Nicht zuletzt ist die Datenlage zur Therapie von Patientinnen mit Hypophysenerkrankungen während der Schwangerschaft sehr eingeschränkt. Es wurde eine selektive Literaturrecherche nach Publikationen mit dem Ziel durchgeführt, die Evidenz zur Diagnostik und Therapie von Hypophysenerkrankungen in der Schwangerschaft zu beschreiben. Gesucht wurde in den Datenbanken PubMed/MEDLINE inkl. PubMed Central sowie mithilfe des Suchdienstes Livivo (ZBMED). Entsprechend der aktuellen Studienlage werden Empfehlungen zur Betreuung von Patientinnen mit hormoninaktiven und hormonaktiven Hypophysenadenomen (Prolaktinom, Akromegalie und Morbus Cushing), Hypophyseninsuffizienz sowie Hypophysenapoplex und Hypophysitis in der
Schwangerschaft gegeben. Am besten ist sicherlich die Behandlung des Prolaktinoms etabliert, zurückzuführen auf die Inzidenz und speziellen Auswirkungen auf die Fertilität. Bei bestätigter Schwangerschaft sollte die dopaminagonistische Therapie des Prolaktinoms unterbrochen werden. Während Mikroprolaktinome nach Absetzen des Dopaminagonisten äußerst selten signifikant an Größe zunehmen, kann es bei Makroprolaktinomen zu symptomatischem Tumorwachstum kommen. In diesem Fall kann eine dopaminagonistische Therapie wieder aufgenommen werden, bei einem primär großen Tumor mit deutlich erhöhtem Wachstumsrisiko ggf. auch von Beginn an fortgeführt werden. Der Kinderwunsch vieler Paare kann trotz Hypophysenerkrankung eines Partners mit ärztlicher Unterstützung bei der Planung und Kontrolle der Schwangerschaft häufig erfüllt werden. Vor dem Hintergrund der Komplexität dieser Erkrankungen sollte die Betreuung schwangerer Patientinnen mit hypophysären Erkrankungen multidisziplinär in Zentren erfolgen, deren Schwerpunkt in der Diagnostik und Therapie von Hypophysenerkrankungen liegt.

\section{Introduction}

During normal pregnancy, the endocrine system and metabolism of the pituitary gland undergoes significant changes as a result of placental hormone secretions. The pituitary gland increases in volume due to hyperplasia of the prolactin cells and changes in pituitary hormone secretions [1]. Prolactin levels rise throughout the entire pregnancy, with the placenta also taking over the synthesis of growth hormone $(\mathrm{GH})$ and suppressing pituitary $\mathrm{GH}$ [2]. $\mathrm{GH}$ levels continue to rise until the 36th/37th week of pregnancy, achieving levels which are many times higher than before the start of pregnancy. Insulin-like growth factor 1 (IGF-1) levels may initially drop, but towards the end of pregnancy they will also be higher than at the start of pregnancy. The placenta additionally synthesizes corticotropin-releasing hormone (CRH), which stimulates the release of adrenocorticotropic hormone (ACTH) and cortisol. In the first trimester of pregnancy placental human chorionic gonadotropin (hCG) stimulates the thyroid, and the liver increases its synthesis of binding proteins [3]. The rise of binding globulins is followed by an increase in the concentrations of total thyroxine (T4) and cortisol until the 16th-20th week of pregnancy $[1,4]$.

Pituitary disorders are rare and may be accompanied by disorders of gonadal function and fertility. The diagnosis and treatment of pituitary disorders in pregnancy represents a special clinical challenge, not least because there is very little data on the treatment of pregnant patients with pituitary disorders. There are very few treatment recommendations, and they are often based on the approach used to treat non-pregnant women and attempt to take the specific physiology of pregnancy into consideration. Because the overall data is limited, this publication aims to provide a summary of the diagnosis and treatment of pituitary disorders in pregnancy. To this end, a search of the literature was carried out using the databases PubMed/MEDLINE together with
PubMed Central and the Livivo (ZB MED) search engine. The search terms used were "pregnancy" or "Schwangerschaft" combined with the respective disease, e.g. "pituitary apoplexy" or "Hypophysenapoplex". The publications found in the databases and the authors' own experience were discussed by all of the authors at several meetings and the authors reached a consensus about the recommended treatment.

This review will start by discussing various aspects relating to tumors which occur in the region of the sella turcica in the order of their frequency of occurrence and then look at different types of pituitary axis insufficiency. The final part will consider issues of fertility in patients with pituitary disorders.

\section{Review}

\section{Pituitary adenomas}

\section{Prolactinoma}

Female patients with hyperprolactinemia almost always present with hypogonadotropic or normogonadotropic hypogonadism. This can usually be resolved by the administration of a dopamine agonist [5]. Regular ovulatory cycles usually return after therapy with a dopamine agonist is initiated, and spontaneous conception is possible in most cases. Dopamine agonist therapy should be discontinued as soon as the pregnancy has been confirmed [5]. Based on current data, taking the dopamine agonists cabergoline and bromocriptine during the period of conception and in early pregnancy does not pose a significant risk for mother or child [6, 7]. Microprolactinomas $(<1 \mathrm{~cm})$ and small macroprolactinomas limited to the sella turcica $(\geq 1 \mathrm{~cm})$ rarely increase significantly in size even after the administration of dopamine agonists is discontinued; no special therapy is required. However, symptomatic tumor growth may occur during pregnancy in 20 to $30 \%$ of cases with macroprolactinoma [6], although it is not possible to predict 


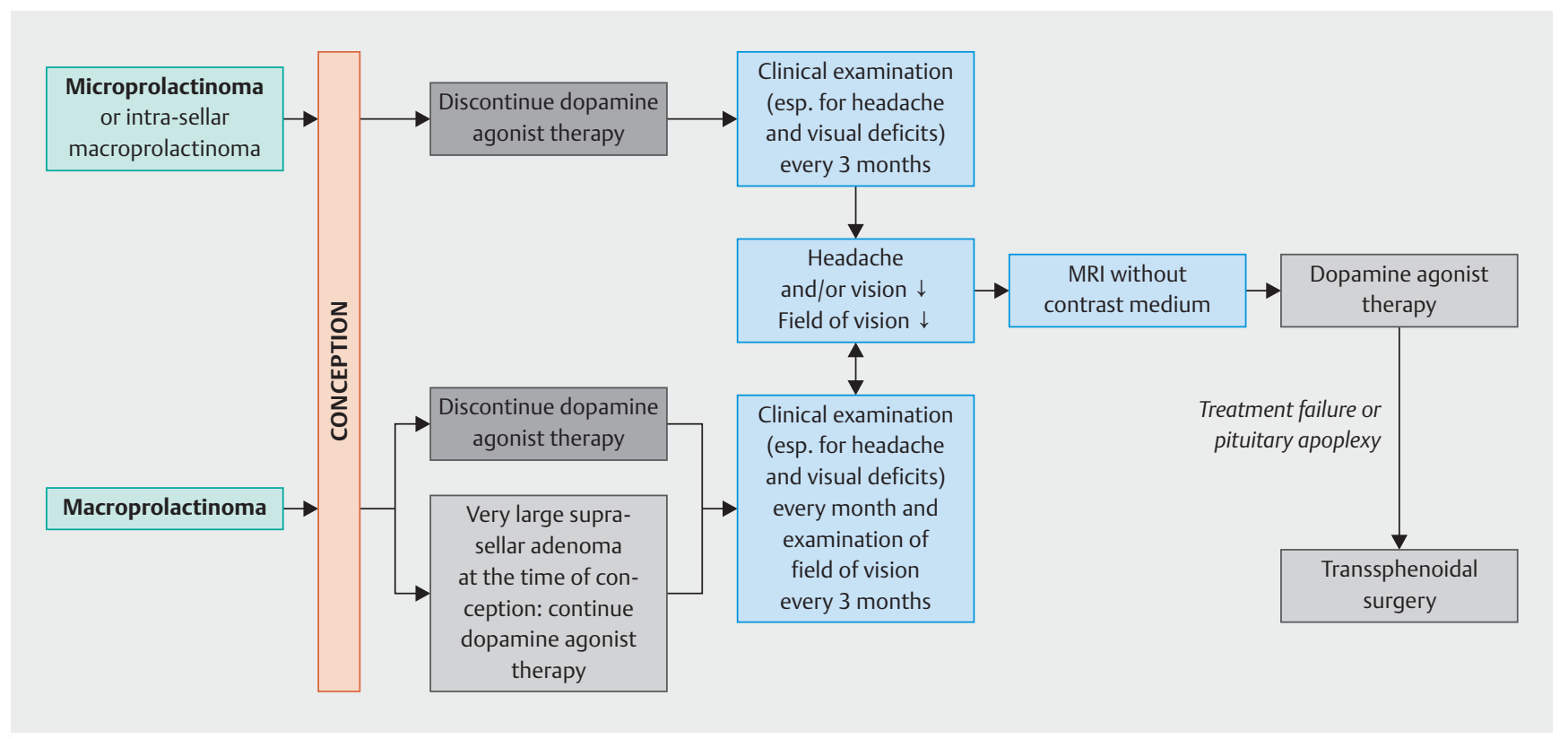

- Fig. 1 Recommendations on the treatment of prolactinoma in pregnancy, modified from $[3,5,8]$.

the growth behavior of the tumor. In principle, female patients with macroprolactinoma should only consider pregnancy after medical therapy has been shown to be effective or after surgery of the pituitary adenoma. The treatment options must be individually discussed with the patient before the start of pregnancy [6, 7] ( $\triangleright$ Fig. 1). If the patient develops local symptoms such as headache or impaired vision during pregnancy due to growth of the tumor, then treatment with a dopamine agonist can be resumed; in cases with a large primary macroprolactinoma and a significant risk of tumor growth, treatment with a dopamine agonist may be continued from the start of pregnancy.

During pregnancy, patients with microprolactinoma should have a clinical examination every 3 months, with a particular focus on any headaches or visual impairments. It is recommended that patients with macroprolactinoma should have a clinical examination every month and visual field testing every three months [3, 5 , 8]. The question whether prolactin values need to be measured regularly during pregnancy is still controversially discussed [9]; the authors are of the opinion that regular monitoring of prolactin levels is only useful for patients with macroprolactinoma. When measuring prolactin levels, the trimester-specific threshold values must also be taken into account [10] ( $\triangleright$ Table 1). Exceeding the threshold values will not trigger any therapeutic consequences per se, but higher prolactin levels could be an indication that the prolactinoma is growing. In such cases, regular clinical examinations should be stepped up. If the prolactin levels rise to the level of the values measured at diagnosis, magnetic resonance imaging (MRI) may be indicated.

Regular clinical examinations and visual field testing is more important than measuring changes in prolactin levels $[6,11]$. Magnetic resonance imaging without gadolinium is indicated for patients with macroprolactinoma and a pronounced rise in prolactin levels, symptoms such as persistent headache, visual impairment or reduced visual field $[6,11]$.

An asymptomatic prolactinoma is not a contra-indication for breastfeeding. Up to $35 \%$ of patients with microprolactinoma appear to be cured after pregnancy [12], probably either as a result of ischemia/necrosis of the adenoma or because of regressive transformation during the pregnancy. The administration of dopamine agonists should only be restarted after the patient has stopped breastfeeding [6].

\section{Hormone-inactive pituitary adenoma/other tumors in the region of the sella turcica}

If the patient has a macroadenoma which was detected prior to conception, the risk of developing Sheehan syndrome post par-

- Table 1 Median prolactin concentrations in each trimester (10th-90th percentile) in uncomplicated pregnancies [10].

\begin{tabular}{|c|c|c|c|}
\hline Prolactin, ng/ml & All $(n=50)$ & Primipara $(n=25)$ & Multipara $(n=25)$ \\
\hline 1st trimester & $28.8(16.3-57.6)$ & $32.6(19.8-63.3)$ & $27.6(10.6-47.0)$ \\
\hline 2nd trimester & $126(54.9-206)$ & $105(49.0-181)$ & $139(72-206)$ \\
\hline 3rd trimester & $216(124-318)$ & $177(115-258)$ & $225(133-320)$ \\
\hline
\end{tabular}


tum must be discussed with the patient; if the adenoma appears to be growing such that there could be a partial loss of pituitary functions and/or chiasma syndrome, surgery should be considered prior to conception. The aim must be to weigh up potential complications of surgery such as pituitary insufficiency against the risk created by the size of the tumor and its proximity to the optic chiasm.

In general, hormone-inactive pituitary adenomas do not increase in size during pregnancy [8], meaning that observant management is initially recommended. Patients with hormone-inactive pituitary adenoma do not have an increased risk for premature birth, arterial hypertension, preeclampsia or stillbirth [13]. Nevertheless, the pregnancy-related increase in pituitary volume may adversely affect other partial functions of the pituitary gland due to hyperplasia of the lactotropic cells, visual impairments caused by cranial nerve lesions (in particular, compression of the chiasm of the optic nerve, more rarely of the sixth cranial nerve) or headaches. Patients newly diagnosed with headaches should have their visual field and vision examined and should be monitored regularly with repeat examinations every 4 weeks during pregnancy. Surgery may be necessary if the adenoma increases in size and the patient presents with serious visual impairment or tumor apoplexy [14]. In such cases, the second trimester is considered the most suitable period for surgery, as by that time organogenesis is complete and surgery becomes more difficult when the pregnancy is more advanced [15]. Alternatively, if surgery is contraindicated or the patient is cautious about undergoing surgery, treatment with a dopamine agonist may be discussed, although there are very few studies which have investigated this option [8, $16]$. The latter study in particular offers practical pointers: cabergoline was mainly used at a mean dose of $1.5 \mathrm{mg} /$ week (maximum dose: $3.5 \mathrm{mg} /$ week). Patients receiving therapy must be closely monitored with frequent clinical and ophthalmic examinations. This therapeutic approach must be discontinued if the visual impairment increases. It is not possible to use changes in prolactin levels to monitor the success of therapy!

There is no reason for patients with a hormone-inactive pituitary adenoma to give birth by $\mathrm{C}$-section and no reason not to breastfeed [17].

In addition to pituitary adenomas, numerous other tumors (e.g. craniopharyngioma, meningiomas), cystic (e.g. Rathke's cleft cyst, arachnoid cyst) and vascular (aneurysms) changes can develop in the pituitary region. For all of these entities, the endocrine diagnosis (which is based on determination of basal hormone levels for prolactin, IGF-1, free T4 [fT4], morning [salivary] cortisol levels) and treatment with regard to a planned pregnancy are analogous to that used for pituitary adenomas. Because of the relationship between the levels of circulating sex hormones and tumor growth, studies have reported that meningiomas increase in size during pregnancy $[18,19]$. If the tumor is known to be present before the patient conceives, removal of the tumor before conception should be considered in the same way as for hormoneinactive macroadenomas [20]. Before planning a pregnancy, patients with any processes in the pituitary region should receive additional neurosurgical counselling.

\section{Acromegaly}

Acromegaly is characterized by the increased secretion of circulating $\mathrm{GH}$. The cause in more than $99 \%$ of cases is a benign $\mathrm{GH}$-secreting tumor [21]. Other causes, for example a tumor secreting $\mathrm{GH}$-releasing hormone (GHRH), are very rare [22]. $\mathrm{GH}$ and the target hormone IGF-1 which is synthesized in the liver do no cross the placental barrier [2], meaning that the infant is not affected by maternal acromegaly. According to retrospective case studies, active acromegaly in pregnancy is associated with a risk of the patient developing gestational diabetes and hypertension [23, 24]. Somatotropic adenomas do not usually increase in size during pregnancy, with the possible exception of increased growth due to a "rebound" phenomenon after discontinuing therapy with somatostatin analogs.

Prior to conception, therapeutic options include surgical (usually transsphenoidal pituitary surgery), medical and radiotherapeutic procedures, which can be used as either primary or secondary treatment [25]. Medical therapy options include somatostatin analogs, dopamine agonists and the $\mathrm{GH}$-receptor antagonist pegvisomant. It is recommended that women of child-bearing age treated with medication use effective contraceptive methods [26]. In case they have conceived, they should discontinue their acromegaly medication [24]. Therapy with a dopamine agonist may be considered for patients with tumors which extend to the chiasm or show invasive growth. The most data on the use of drugs in pregnancy is available for somatostatin analogs and the dopamine agonists bromocriptine and cabergoline [26]; continuation of therapy using somatostatin analogs during pregnancy has been described in case reports and small series $[2,23,27]$. There were no indications of teratogenicity or an increased rate of malformations. However, intrauterine growth retardation following treatment with somatostatin analogs was reported in individual cases [24]. The least data is currently available on the use of pegvisomant in pregnancy, and it should only be administered in exceptional cases during pregnancy $[28,29]$.

Large adenomas which extend to the chiasm should be evaluated clinically every three months with examination of the patient's field of vision. Magnetic resonance imaging (MRI) may be indicated in patients who present with persistent headache, reduced vision or reduced field of vision, with MRI usually carried out without gadolinium, although contrast media may be used if necessary.

Patients with microadenoma who are not receiving medication and patients who have undergone surgical resection of a macroadenoma can breastfeed after an uncomplicated pregnancy [26]. Breastfeeding is contraindicated for patients receiving treatment with bromocriptine or cabergoline [26], and for somatostatin analogs or pegvisomant, as it is currently not known whether these substances pass into human breast milk [30-32]

Biochemical monitoring of acromegaly is difficult during pregnancy, as measured growth hormone concentrations increasingly mirror the production of placental $\mathrm{GH}$ over the course of the pregnancy and do not adequately reflect the activity of the somatotropic pituitary adenoma. Because of the high estrogen levels, IGF-1 levels usually drop at the start of pregnancy but increase again thereafter due to the effect of placental $\mathrm{GH}$ [2]. 


\section{Cushing's disease}

Patients with florid Cushing's disease rarely become pregnant due to the effect of hypercortisolism on the gonadal axis [33]. Fertility during remitting disease appears to correspond to that of the normal female population [34]. According to a systematic review of all 263 cases of pregnancy published between 1952 and 2015, pregnancy with active Cushing's syndrome is often associated with diabetes mellitus, arterial hypertension, preeclampsia, maternal miscarriage as well as neonatal health problems [33]. Pregnancy during active disease is therefore inadvisable [33].

It is difficult to obtain an accurate diagnosis during pregnancy if there is a suspicion of newly occurring or recurrence of Cushing's syndrome, not least because symptoms such as weight gain, glucose intolerance, hypertension, striae and mood swings can also be pregnancy-related. Physiologically, the excretion of free cortisol in urine (UFC) over a period of 24 hours doubles or triples in the first and second trimester [35], while the suppression of cortisol measured by the dexamethasone suppression test is reduced over the same period [36]. As the circadian cortisol rhythm remains the same in pregnancy (although with higher evening levels), alternative methods for cortisol determination include determining salivary cortisol levels or midnight serum cortisol test. When measuring UFC [37], only values which are more than triple the upper limit of standard levels are relevant as indications for disease. The treatment of Cushing's disease during pregnancy depends on how active the disease is, as activity can range from mild hypercortisolism to aggressive disease. Whether transsphenoidal surgery should be considered during pregnancy depends on the MRI findings and the patient's previous medical history/previous surgeries [38]. Individual reports have been published describing the use of drugs to treat Cushing's disease during pregnancy, particularly the administration of metyrapone [39]. Considering its (limited) efficacy in non-pregnant patients [40,41] treatment with the dopamine agonist cabergoline could be tried $[42,43]$. Bilateral adrenalectomy may also represent an option, serving as a means of last resort to manage aggressive, uncontrolled progressive disease during pregnancy $[38,39,44]$. In a retrospective analysis of 136 pregnant women with Cushing's syndrome, unilateral or bilateral adrenalectomy was carried out in 31 patients; the rate of live births in this cohort was $87 \%$ [38].

\section{Lymphocytic hypophysitis}

Lymphocytic hypophysitis is a rare autoimmune disease in which the pituitary gland is infiltrated by lymphocytes, plasma cells and macrophages [45]. In earlier publications, lymphocytic hypophysitis was predominantly reported in young women during or after pregnancy. More recent data suggest that this may have been a publication bias as an association between lymphocytic hypophysitis and pregnancy constitutes a distinctive constellation of symptoms [46]. It is often associated with other autoimmune diseases. In pregnancy, lymphocytic hypophysitis predominantly appears in the third trimester (cf. Honegger and Giese for an overview [46]). Early symptoms and imaging findings are often unspecific. Suggestive clinical symptoms are central diabetes insipidus and an unusual sequence of anterior pituitary lobe axis dysfunction (e.g. starting with the corticotropic hormone axis). Diagnostic pointers include thickened hypophyseal stalk, loss of the typi- cally bright pituitary posterior lobe ("bright spot”) on T1-weighted MRI and a homogeneously tent-shaped pituitary gland with an intact, non-expanded sellar floor $[46,47]$. Detection of hypophyseal autoantibodies is not, as yet, diagnostically important. In addition to adequate hormone replacement therapy, treatment for patients experiencing visual deterioration and chiasma syndrome due to lesion expansion can consist of glucocorticoid therapy [48]. However, this is associated with a high rate of recurrence and, according to recent studies, its efficacy is limited [49]. Surgery during pregnancy may be considered in a few cases, particularly for patients with progressive deterioration of vision and reduced visual field acuity for whom glucocorticoid therapy was ineffective [38]. If symptoms are mild, treatment should be postponed until after the birth [46].

\section{Pituitary apoplexy}

Pituitary apoplexy is the term used to describe acute bleeding into the anterior pituitary or the infarction of a pre-existing pituitary adenoma [50]. A macroadenoma is present in more than $80 \%$ of cases. Typical symptoms are severe headache ("thunderclap headache"), visual deficits, double vision and altered mental status; they may be accompanied by symptoms of acute adrenocortical insufficiency. However, there may also be less clinically visible presenting symptoms. Risk factors for pituitary apoplexy are cardiovascular and other major surgical procedures, as well as hormone treatment, endocrine tests or taking anticoagulants [51]. Because of the associated hypertrophy of lactotropic cells and the increase in normal pituitary volume, pregnancy is also considered a risk factor for pituitary apoplexy [52]. Suggested causes for pituitary apoplexy include expansion of a tumor beyond the limits of its vascular supply and changes in the perfusion characteristics of the hormonally stimulated pituitary [50]. If the clinical symptoms only present in the form of headache and/or hormonal deficiencies, the recommended approach during pregnancy is usually surveillance combined with adequate substitution of the deficient hormone axis as well as the administration of a dopamine agonist if bleeding into a prolactinoma occurred [52]. Primary neurosurgical therapy should be discussed for patients with neuro-ophthalmological symptoms caused by a large symptomatic lesion. It is important to differentiate Sheehan syndrome (i.e., acute ischemic necrosis of the anterior pituitary due to extensive loss of blood and hypovolemic shock during childbirth) from pituitary apoplexy [53].

\section{Pituitary insufficiency}

Functional pituitary disorders can result from many different diseases occurring in the hypothalamic and pituitary region. In addition to hormone deficits due to pituitary adenoma, disorders may be caused by infections, radiotherapy, hypophysitis, pituitary apoplexy and metastasis [54]. Endocrine disorders are characterized by the partial loss of individual anterior pituitary functions (thyrotropic, gonadotropic, somatotropic and/or corticotropic insufficiency), posterior pituitary function (diabetes insipidus) or complete pituitary insufficiency. Pituitary insufficiency is associated with an increased risk of pregnancy complications such as miscarriage, anemia, pregnancy-related hypertension, placental abruption, premature birth and postpartum bleeding [55 - 57]. 
- Table 2 Reference ranges for fT4 in standard tests by five suppliers [59].

\begin{tabular}{|c|c|c|c|c|c|c|}
\hline \multirow[b]{3}{*}{ Percentile } & \multicolumn{6}{|c|}{ fT4 in pmol/l } \\
\hline & \multicolumn{2}{|c|}{ First trimester } & \multicolumn{2}{|c|}{ Second trimester } & \multicolumn{2}{|c|}{ Third trimester } \\
\hline & 2.5 & 97.5 & 2.5 & 97.5 & 2.5 & 97.5 \\
\hline Architect (8 studies) & 11.1 & 18.5 & 9.8 & 16.3 & 8.6 & 14.6 \\
\hline Beckman (4 studies) & 7.6 & 14.7 & 6.0 & 12.5 & 5.3 & 11.6 \\
\hline Centaur (6 studies) & 11.8 & 19.4 & 10.6 & 17.6 & 9.2 & 16.7 \\
\hline Immulite (5 studies) & 11.0 & 18.0 & 10.3 & 17.4 & & \\
\hline Roche (7 studies) & 12.2 & 20.4 & 9.8 & 15.9 & 9.0 & 15.9 \\
\hline
\end{tabular}

The following sections provide information on the endocrine diagnosis of and therapy for specific functional losses of the anterior and posterior pituitary in pregnancy, including oxytocin deficiency. The management of pregnant women with complete pituitary insufficiency must be guided by the respective partial insufficiencies.

\section{Secondary hypothyroidism}

Because of the strong rise in human chorionic gonadotropin (hCG) during pregnancy with binding to the TSH receptor, a physiological decrease in TSH is often observed [58]. However, thyroid hormone substitution in patients with secondary hypothyroidism (thyrotropic insufficiency) must be guided by the levels of free thyroxine (fT4). Care must be taken when evaluating fT4 levels in pregnancy as the significant changes in protein and hormone levels that occur in pregnancy prevent accurate determination of fT4 levels using standard immunoassays [58]. During pregnancy, fT4 pregnancy-specific ranges apply [59] ( Table 2 ). The aim should be to achieve values within the upper normal range. As the methods for measuring total thyroxine are less prone to interference, an alternative option could be to measure total thyroxine levels from the 16th week of gestation, with normal ranges increased by $50 \%$ to account for pregnancy changes [4].

During pregnancy, l-thyroxine dosages often have to be increased by up to $50 \%$ compared to pre-pregnancy dosages because of the increase in binding globulins $[60,61]$. But because it is not possible to estimate the quantitative impact of thyroid stimulation with hCG, in some cases the I-thyroxine dosage may even have to be reduced $[60,61]$.

Up until at least the 12th week of gestation, the mother is the only source of thyroid hormones. Studies have suggested that maternal hypothyroxinemia may be associated with cognitive delays in early childhood [62]. The thyroid status of pregnant patients with secondary hypothyroidism should therefore be evaluated every 4 weeks.

\section{Secondary adrenocortical insufficiency}

Hypoglycemia, pituitary function failure or local symptoms caused by a pituitary lesion should also raise suspicion of secondary adrenocortical insufficiency (corticotropic insufficiency) [63]. Because of the massive increase in binding globulins, it is very difficult to interpret cortisol levels in serum correctly during preg- nancy, and they are of only limited value for diagnosing adrenal gland insufficiency. However, in all three trimesters of pregnancy morning salivary cortisol levels do not differ significantly from those of healthy non-pregnant women [64]. The determination of morning salivary cortisol, preferably obtained during stress (e.g., "a cold shower"), is a useful first step to screen for adrenocortical insufficiency $[65,66]$. The most extensive data available on stimulation tests is for the $250 \mu \mathrm{g}$ ACTH stimulation test. In this test, the cortisol serum threshold values in the second and third trimester are 60-80\% higher than for non-pregnant women [67]. A peak cortisol value of $>30 \mu \mathrm{g} / \mathrm{dl}(828 \mathrm{nmol} / \mathrm{I})$ is considered to exclude adrenocortical insufficiency [63]. Low dose $(1 \mu \mathrm{g})$ ACTH stimulation tests provide a correct diagnosis in the majority of patients with threshold values of $18-20 \mu \mathrm{g} / \mathrm{dl}(497-553 \mathrm{nmol} / \mathrm{l})$, while values of more than $30 \mu \mathrm{g} / \mathrm{dl}(828 \mathrm{nmol} / \mathrm{I})$ in all probability exclude adrenocortical insufficiency [68]. Insulin hypoglycemia and metyrapone stimulation tests are contra-indicated in pregnancy [69].

Adequate glucocorticoid substitution is important, as is careful monitoring to prevent over-substitution. The standard substitution dosage usually does not have to be increased in the first and second trimester of pregnancy but sometimes in the third trimester due to the increase in binding globulins [63]. It is essential that the expectant mother is trained to recognize the signs of adrenal crisis, is prescribed emergency medication and given an emergency card and that information is sent in writing to the obstetrician who will attend the birth. During the birth, the patient should receive a $50 \mathrm{mg}$ bolus of hydrocortisone, followed by continuous infusion of 100 to $200 \mathrm{mg} / 24$ hours or $50 \mathrm{mg}$ every 6 hours [63]. The dosage can then be reduced to the normal substitution dosage 1-2 days after giving birth. Medically, there is usually no reason for the birth to be by C-section rather than by vaginal delivery. Post partum the neonate must be monitored for signs of adrenocortical insufficiency.

\section{Growth hormone deficiency}

Patients with anterior pituitary insufficiency and growth hormone deficiency often require assisted pregnancy procedures [70]. There are some indications that growth hormone substitution can improve patients' likelihood of conceiving. Once the pregnancy has been confirmed, growth hormone substitution can usually be terminated [70]. The results of a number of studies have 
- Table 3 Gonadotropin substitution therapy to induce spermatogenesis and maintain androgenization in men $[88,89]$.

\begin{tabular}{|c|c|c|}
\hline Substance & Administration & Dosages \\
\hline \multirow[t]{2}{*}{$\begin{array}{l}\text { Human chorionic gonadotropin (hCG), } \\
\text { e.g. } \text { Brevactid }^{\circledR}\end{array}$} & \multirow[t]{2}{*}{ SC or IM } & $\begin{array}{l}1500 \text { IU, } 2 \text { to } 3 \text { times per week (prepubertal patients should receive } \\
\text { higher doses in the first few months) }\end{array}$ \\
\hline & & $\begin{array}{l}\text { After } 2 \text { months, titrate to achieve mean testosterone levels without } \\
\text { a significant increase in estradiol. }\end{array}$ \\
\hline $\begin{array}{l}\text { Highly purified or recombinant FSH } \\
\left(\text { e.g. Puregon }{ }^{\circledR}, \text { Gonal }^{\circledR} \text { ) }\right.\end{array}$ & SC or IM & $\begin{array}{l}150 \mathrm{IU}, 3 \text { times per week, usually only after } 3 \text { to } 6 \text { months } \\
\text { of previous therapy with hCG }\end{array}$ \\
\hline
\end{tabular}

shown that growth hormone substitution is not required during pregnancy [71]. An alternative to immediately and completely ceasing substitution is to continue substitution, with the dosages adjusted to mimic physiological conditions. In such cases, substitution doses are reduced in the second trimester, and discontinued in the third trimester of pregnancy in parallel to the increases in placental growth hormone secretion [70].

\section{Diabetes insipidus}

Transient diabetes insipidus during pregnancy is primarily caused by increased placental vasopressinase activity and a higher rate of vasopressin degradation in the late second trimester and early third trimester of pregnancy [72]. Because of the greater placental mass, the risk is even higher in multiple pregnancies. Some studies have also reported an association with preeclampsia [73].

Exacerbation or demasking of pre-existing central diabetes insipidus is far rarer [74]. In such cases, symptoms occur even before peak vasopressinase activity is reached. Patients with pituitary disease who have an increased risk for diabetes insipidus and patients with pre-existing diabetes insipidus should be informed about the expected physiological changes and encouraged to regularly monitor how much they drink and how much they excrete. Diagnostic tests are primarily based on the measurement of serum/urine osmolality and the measurement of natrium levels. Pregnant women should not have a fluid deprivation test because of the risk of hypernatremia and dehydration. A lack of vasopressin is not necessarily associated with oxytocin deficiency $[75,76]$.

Therapy consists of the vasopression V2 receptor agonist desmopressin (1-deamino-8-D-arginine vasopressin, DDAVP), usually administered intranasally in the evening. Dosages are usually higher than for non-pregnant patients [77]. After the patient has given birth, the administration of DDAVP to patients with transient diabetes insipidus can be discontinued after a few days or weeks; for patients with pre-existing disease, dosages should be reduced to the doses prescribed prior to pregnancy. A systematic review of 53 cases treated with DDAVP found no serious side effects [78]. The review also found no indications of adverse effects on mother or child when DDAVP was administered during pregnancy and the lactation period. The amount of DDAVP which can be transmitted to the infant through breastmilk is too low to affect the child's diuresis.

\section{Oxytocin deficiciency}

A recently published study suggested that patients with central diabetes insipidus have lower oxytocin levels than controls and that this could be associated with a reduced empathic ability [79]. But this was only investigated in a relatively small, mixed male and female population and never in pregnant patients.

The role of oxytocin in inducing birth in patients with pituitary insufficiency is controversial, and the literature and experience on this point are unfortunately very limited. Mice deficient in oxytocin had normal, spontaneous parturition [80]. In humans, most case reports and case series also report that normal spontaneous birth can occur even in mothers with complete hypophyseal insufficiency $[55,81]$ as it is possible that uterine oxytocin may be responsible for inducing parturition.

\section{Fertility and pituitary disease}

With careful planning and medical support prior to pregnancy, many couples with pituitary disease can fulfil their wish to have children [82]. Spontaneous pregnancy occurs in around half of affected couples.

Before starting assisted reproduction, affected couples should first wait to see whether spontaneous conception is possible. Men can still be fertile even if they present with small testicular volume (less than $3 \mathrm{ml}$ ) and a sperm count of less than $10 \mathrm{million} / \mathrm{ml}$ [83]. During fertility treatment, gonadotropins (i.e., hCG and recombinant follicle-stimulating hormone [rFSH]) are usually administered to men with hypogonadotropic hypogonadism ( $\triangleright$ Table 3 ). Pulsatile GnRH treatment is also a potential option to treat men with hypothalamic deficits. The first spermiogram should usually be done at 6 months after starting therapy, or even 4 months after starting therapy in patients who acquired their hypogonadism after puberty. A first stimulation carried out quite early after the end of puberty would probably lead to significantly faster sperm maturation at a time when the patient wishes to have a child.

The administration of gonadotropins achieves ovulation in most women with hypogonadotropic hypogonadism. Luteinizing hormone (LH) can be used as an alternative to hCG to support FSH-induced follicle maturation [84,85]. Growth hormone deficiency can impair stimulation $[1,86]$. If the patient also has partial impairment of somatotropic functions, growth hormone substitution can increase the probability of conception [87]. An important aspect of successful therapy is that men/women are cared for by 
an experienced endocrinologist/andrologist/gynecologist who is familiar with such problems.

\section{Conclusions}

- In patients with small pituitary tumors, observant management during pregnancy with close monitoring is appropriate, although treatment with antisecretory drugs should be discontinued. Patients with large or symptomatically growing tumors and/or tumors with high disease activity require individually tailored therapies including neurosurgery and/or drugs.

- Prolactinoma therapy with dopamine agonists should be interrupted as soon as the pregnancy is confirmed. Microprolactinomas rarely increase significantly in size if dopamine agonist therapy is discontinued, although symptomatic tumor growth can occur with macroprolactinomas. In such cases, dopamine agonist administration can be resumed; patients with a large primary tumor and a significantly increased risk of tumor growth can be given a dopamine agonist from the start of pregnancy, if necessary.

- When treating pregnant women with secondary hypothyroidism, l-thyroxine substitution should be guided by the thyroid hormone changes (fT4) in normal pregnancies.

- In patients with adrenocortical insufficiency, cortisol substitution doses may sometimes need to be increased in the second half of pregnancy.

- Growth hormone substitution can usually be paused during pregnancy in patients with growth hormone deficits.

- If diabetes insipidus develops during pregnancy, treatment with DDAVP is indicated. Depending on the etiology of the diabetes insipidus, DDAVP may be gradually discontinued after the end of pregnancy or reduced to the dosage given to the patient prior to pregnancy.

\section{Acknowledgements}

The authors were assisted during their compilation of the manuscript by Dr. Joachim Sauer, whose assistance was made possible by an unrestricted grant from Ipsen Pharma $\mathrm{GmbH}$.

\section{Conflict of Interest}

AL received honoraria from Ipsen, Pfizer, Novartis, Merck, Eli Lilly, Sandoz and Novo Nordisk for lectures and/or consultancy work. MCC participated in AdBoards of Ipsen and Novartis and received travel expenses and expenses for conferences from Ipsen and Novartis. IKA and SP received honoraria for lectures and/or consultancy work as well as travel costs from Ipsen, Novartis and Pfizer. MD received honoraria for lectures and/ or consultancy work from Ipsen, Pfizer, Novartis, Sandoz and Shire. RF received travel costs and expenses for conferences and honoraria for lectures from Ipsen, Novartis, Sanofi and Shire. JF participated in AdBoards of Ipsen, Novartis and Bristol-Myers Squibb. JS received honoraria for lectures and consultancy work as well as travel costs from Ipsen, Novartis and Pfizer and participated in studies by Ipsen, Novartis, Pfizer and Chiasma. GS received honoraria for lectures and/or consultancy work and travel costs from Ipsen, Novartis, Novo Nordisk, Pfizer, Sandoz and Shire.

\section{References}

[1] Karaca Z, Tanriverdi F, Unluhizarci K et al. Pregnancy and pituitary disorders. Eur J Endocrinol 2010; 162: 453-475

[2] Muhammad A, Neggers SJ, van der Lely AJ. Pregnancy and acromegaly. Pituitary 2017; 20: 179-184

[3] Glezer A, Jallad RS, Machado MC et al. Pregnancy and pituitary adenomas. Minerva Endocrinol 2016; 41: 341-350

[4] Alexander EK, Pearce EN, Brent GA et al. 2017 Guidelines of the American Thyroid Association for the Diagnosis and Management of Thyroid Disease During Pregnancy and the Postpartum. Thyroid 2017; 27: 315389

[5] Melmed S, Casanueva FF, Hoffman AR et al. Diagnosis and treatment of hyperprolactinemia: an Endocrine Society clinical practice guideline. J Clin Endocrinol Metab 2011; 96: 273-288

[6] Molitch ME. Endocrinology in pregnancy: management of the pregnant patient with a prolactinoma. Eur J Endocrinol 2015; 172: R205-R213

[7] Lebbe M, Hubinont C, Bernard P et al. Outcome of 100 pregnancies initiated under treatment with cabergoline in hyperprolactinaemic women. Clin Endocrinol (Oxf) 2010; 73: 236-242

[8] Molitch ME. Pituitary tumors and pregnancy. Growth Horm IGF Res 2003; 13 (Suppl. A): S38-S44

[9] Almalki MH, Ur E, Johnson M et al. Management of prolactinomas during pregnancy - a survey of four Canadian provinces. Clin Invest Med 2012; 35: E96-E104

[10] Schock H, Zeleniuch-Jacquotte A, Lundin E et al. Hormone concentrations throughout uncomplicated pregnancies: a longitudinal study. BMC Pregnancy Childbirth 2016; 16: 146

[11] Almalki MH, Alzahrani S, Alshahrani F et al. Managing Prolactinomas during Pregnancy. Front Endocrinol (Lausanne) 2015; 6: 85

[12] Schlechte J, Dolan K, Sherman B et al. The natural history of untreated hyperprolactinemia: a prospective analysis. J Clin Endocrinol Metab 1989; 68: 412-418

[13] Lambert K, Rees K, Seed PT et al. Macroprolactinomas and Nonfunctioning Pituitary Adenomas and Pregnancy Outcomes. Obstet Gynecol 2017; 129: 185-194

[14] Galland F, Vantyghem MC, Cazabat L et al. Management of nonfunctioning pituitary incidentaloma. Ann Endocrinol (Paris) 2015; 76: 191-200

[15] Araujo PB, Vieira Neto L, Gadelha MR. Pituitary tumor management in pregnancy. Endocrinol Metab Clin North Am 2015; 44: 181-197

[16] Greenman Y, Cooper O, Yaish I et al. Treatment of clinically nonfunctioning pituitary adenomas with dopamine agonists. Eur J Endocrinol 2016; 175: 63-72

[17] Chanson P, Raverot G, Castinetti F et al. Management of clinically nonfunctioning pituitary adenoma. Ann Endocrinol (Paris) 2015; 76: 239247

[18] Lusis EA, Scheithauer BW, Yachnis AT et al. Meningiomas in pregnancy: a clinicopathologic study of 17 cases. Neurosurgery 2012; 71: 951-961

[19] Moscovici S, Fraifeld S, Cohen JE et al. Parasellar meningiomas in pregnancy: surgical results and visual outcomes. World Neurosurg 2014; 82: e503-e512

[20] Laviv Y, Bayoumi A, Mahadevan A et al. Meningiomas in pregnancy: timing of surgery and clinical outcomes as observed in 104 cases and establishment of a best management strategy. Acta Neurochir (Wien) 2018; 160: 1521-1529

[21] Melmed S. Acromegaly. N Engl J Med 1990; 322: 966-977

[22] Thorner MO, Frohman LA, Leong DA et al. Extrahypothalamic growthhormone-releasing factor (GRF) secretion is a rare cause of acromegaly: plasma GRF levels in 177 acromegalic patients. J Clin Endocrinol Metab 1984; 59: 846-849 
[23] Fleseriu M. Medical treatment of acromegaly in pregnancy, highlights on new reports. Endocrine 2015; 49: 577-579

[24] Caron P, Broussaud S, Bertherat J et al. Acromegaly and pregnancy: a retrospective multicenter study of 59 pregnancies in 46 women. J Clin Endocrinol Metab 2010; 95: 4680-4687

[25] Katznelson L, Laws ER jr., Melmed S et al. Acromegaly: an endocrine society clinical practice guideline. J Clin Endocrinol Metab 2014; 99: $3933-$ 3951

[26] Caron P. Acromegaly and pregnancy. Ann Endocrinol (Paris) 2011; 72: 282-286

[27] Jallad RS, Shimon I, Fraenkel M et al. Outcome of pregnancies in a large cohort of women with acromegaly. Clin Endocrinol (Oxf) 2018; 88: 896907

[28] Brian SR, Bidlingmaier M, Wajnrajch MP et al. Treatment of acromegaly with pegvisomant during pregnancy: maternal and fetal effects. J Clin Endocrinol Metab 2007; 92: 3374-3377

[29] van der Lely AJ, Gomez R, Heissler JF et al. Pregnancy in acromegaly patients treated with pegvisomant. Endocrine 2015; 49: 769-773

[30] Novartis Pharma GmbH. Sandostatin ${ }^{\circledR}$ LAR $^{\circledR}$-Fachinformation. Stand: Februar 2018

[31] Pfizer Pharma GmbH. Somavert ${ }^{\circledR}$ Fachinformation. Stand August 2018

[32] Ipsen Pharma GmbH. Somatuline ${ }^{\circledR}$ Fachinformation. Stand Februar 2015

[33] Caimari F, Valassi E, Garbayo P et al. Cushing's syndrome and pregnancy outcomes: a systematic review of published cases. Endocrine 2017; 55 : 555-563

[34] Caimari F, Corcoy R, Webb SM. Cushing's disease: major difficulties in diagnosis and management during pregnancy. Minerva Endocrinol 2018; 43: 435-445. doi:10.23736/S0391-1977.18.02803-1

[35] Carr BR, Parker CR jr., Madden JD et al. Maternal plasma adrenocorticotropin and cortisol relationships throughout human pregnancy. Am J Obstet Gynecol 1981; 139: 416-422

[36] Odagiri E, Ishiwatari N, Abe $\mathrm{Y}$ et al. Hypercortisolism and the resistance to dexamethasone suppression during gestation. Endocrinol Jpn 1988; 35: 685-690

[37] Viardot A, Huber P, Puder JJ et al. Reproducibility of nighttime salivary cortisol and its use in the diagnosis of hypercortisolism compared with urinary free cortisol and overnight dexamethasone suppression test. J Clin Endocrinol Metab 2005; 90: 5730-5736

[38] Lindsay JR, Jonklaas J, Oldfield EH et al. Cushing's syndrome during pregnancy: personal experience and review of the literature. J Clin Endocrinol Metab 2005; 90: 3077-3083

[39] Bronstein MD, Machado MC, Fragoso MC. Management of endocrine disease: management of pregnant patients with Cushing's syndrome. Eur J Endocrinol 2015; 173: R85-R91

[40] Burman P, Eden-Engstrom B, Ekman B et al. Limited value of cabergoline in Cushing's disease: a prospective study of a 6-week treatment in 20 patients. Eur J Endocrinol 2016; 174: 17-24

[41] Pivonello R, De Martino MC, Cappabianca P et al. The medical treatment of Cushing's disease: effectiveness of chronic treatment with the dopamine agonist cabergoline in patients unsuccessfully treated by surgery. J Clin Endocrinol Metab 2009; 94: 223-230

[42] Nakhleh A, Saiegh L, Reut M et al. Cabergoline treatment for recurrent Cushing's disease during pregnancy. Hormones (Athens) 2016; 15: 453-458

[43] Woo I, Ehsanipoor RM. Cabergoline therapy for Cushing disease throughout pregnancy. Obstet Gynecol 2013; 122: 485-487

[44] Reincke M, Ritzel K, Osswald A et al. A critical reappraisal of bilateral adrenalectomy for ACTH-dependent Cushing's syndrome. Eur J Endocrinol 2015; 173: M23-M32

[45] Chrisoulidou A, Boudina M, Karavitaki N et al. Pituitary disorders in pregnancy. Hormones (Athens) 2015; 14: 70-80
[46] Honegger ], Giese S. Acute pituitary disease in pregnancy: how to handle hypophysitis and Sheehan's syndrome? Minerva Endocrinol 2018; 43: 465-475

[47] Faje A, Tritos NA, Swearingen B, Klibanski A. Neuroendocrine Disorders: pituitary Imaging. In: Masdeu JC, González RG, eds. Handbook of clinical Neurology, Neuroimaging, Part II. Amsterdam, Niederlande: Elsevier; 2016: 873-885

[48] Broekman M, Goedee SH, Nieuwlaat WA et al. Corticosteroid treatment buys time in case of a newly diagnosed hypophysitis with visual deterioration. BMJ Case Rep 2013. doi:10.1136/bcr-2013-010035

[49] Honegger J, Buchfelder M, Schlaffer S et al. Treatment of Primary Hypophysitis in Germany. J Clin Endocrinol Metab 2015; 100: 3460-3469

[50] Oldfield EH, Merrill M]. Apoplexy of pituitary adenomas: the perfect storm. J Neurosurg 2015; 122: 1444-1449

[51] Grzywotz A, Kleist B, Moller LC et al. Pituitary apoplexy - A single center retrospective study from the neurosurgical perspective and review of the literature. Clin Neurol Neurosurg 2017; 163: 39-45

[52] Grand'Maison S, Weber F, Bedard MJ et al. Pituitary apoplexy in pregnancy: A case series and literature review. Obstet Med 2015; 8: 177-183

[53] Karaca Z, Laway BA, Dokmetas HS et al. Sheehan syndrome. Nat Rev Dis Primers 2016; 2: 16092

[54] Prabhakar VK, Shalet SM. Aetiology, diagnosis, and management of hypopituitarism in adult life. Postgrad Med J 2006; 82: 259-266

[55] Kubler K, Klingmuller D, Gembruch U et al. High-risk pregnancy management in women with hypopituitarism. J Perinatol 2009; 29: 89-95

[56] Overton CE, Davis C], West C et al. High risk pregnancies in hypopituitary women. Hum Reprod 2002; 17: 1464-1467

[57] Davis LE, Leveno KJ, Cunningham FG. Hypothyroidism complicating pregnancy. Obstet Gynecol 1988; 72: 108-112

[58] Stagnaro-Green A, Abalovich M, Alexander E et al. Guidelines of the American Thyroid Association for the diagnosis and management of thyroid disease during pregnancy and postpartum. Thyroid 2011; 21: $1081-1125$

[59] McNeil AR, Stanford PE. Reporting Thyroid Function Tests in Pregnancy. Clin Biochem Rev 2015; 36: 109-126

[60] Alexander EK, Marqusee E, Lawrence ] et al. Timing and magnitude of increases in levothyroxine requirements during pregnancy in women with hypothyroidism. N Engl J Med 2004; 351: 241-249

[61] Stagnaro-Green A, Abalovich M, Alexander E et al. Guidelines of the American Thyroid Association for the diagnosis and management of thyroid disease during pregnancy and postpartum. Thyroid 2011; 21: 1081-1125

[62] Henrichs J, Bongers-Schokking J], Schenk J] et al. Maternal thyroid function during early pregnancy and cognitive functioning in early childhood: the generation R study. J Clin Endocrinol Metab 2010; 95: 42274234

[63] Lindsay JR, Nieman LK. The hypothalamic-pituitary-adrenal axis in pregnancy: challenges in disease detection and treatment. Endocr Rev 2005; 26: 775-799

[64] Ambroziak U, Kondracka A, Bartoszewicz Z et al. The morning and latenight salivary cortisol ranges for healthy women may be used in pregnancy. Clin Endocrinol (Oxf) 2015; 83: 774-778

[65] Yuen KC, Chong LE, Koch CA. Adrenal insufficiency in pregnancy: challenging issues in diagnosis and management. Endocrine 2013; 44: 283-292

[66] Langlois F, Lim DST, Fleseriu M. Update on adrenal insufficiency: diagnosis and management in pregnancy. Curr Opin Endocrinol Diabetes Obes 2017; 24: 184-192

[67] Nolten WE, Lindheimer MD, Oparil S et al. Desoxycorticosterone in normal pregnancy. I. Sequential studies of the secretory patterns of desoxycorticosterone, aldosterone, and cortisol. Am J Obstet Gynecol 1978; 132: $414-420$ 
[68] McKenna DS, Wittber GM, Nagaraja HN et al. The effects of repeat doses of antenatal corticosteroids on maternal adrenal function. Am J Obstet Gynecol 2000; 183: 669-673

[69] Schulte HM, Weisner D, Allolio B. The corticotrophin releasing hormone test in late pregnancy: lack of adrenocorticotrophin and cortisol response. Clin Endocrinol (Oxf) 1990; 33: 99-106

[70] Vila G, Akerblad AC, Mattsson AF et al. Pregnancy outcomes in women with growth hormone deficiency. Fertil Steril 2015; 104: 1210-1217.e1

[71] Curran AJ, Peacey SR, Shalet SM. Is maternal growth hormone essential for a normal pregnancy? Eur J Endocrinol 1998; 139: 54-58

[72] Davison JM, Sheills EA, Philips PR et al. Metabolic clearance of vasopressin and an analogue resistant to vasopressinase in human pregnancy. Am J Physiol 1993; 264: F348-F353

[73] Katz VL, Bowes WA jr. Transient diabetes insipidus and preeclampsia. South Med J 1987; 80: 524-525

[74] Bellastella A, Bizzarro A, Colella $C$ et al. Subclinical diabetes insipidus. Best Pract Res Clin Endocrinol Metab 2012; 26: 471-483

[75] Sende P, Pantelakis N, Suzuki K et al. Plasma oxytocin determinations in pregnancy with diabetes insipidus. Obstet Gynecol 1976; 48: 38S-41S

[76] Cobo E, De Bernal M, Gaitan E. Low oxytocin secretion in diabetes insipidus associated with normal labor. Am J Obstet Gynecol 1972; 114: 861866

[77] Quigley J, Shelton C, Issa B et al. Diabetes insipidus in pregnancy. Obstet Gynaecol 2018; 20: 41-48

[78] Ray JG. DDAVP use during pregnancy: an analysis of its safety for mother and child. Obstet Gynecol Surv 1998; 53: 450-455

[79] Daughters K, Manstead ASR, Rees DA. Hypopituitarism is associated with lower oxytocin concentrations and reduced empathic ability. Endocrine 2017; 57: 166-174

[80] Nishimori K, Young L], Guo Q et al. Oxytocin is required for nursing but is not essential for parturition or reproductive behavior. Proc Natl Acad Sci U S A 1996; 93: 11699-11704
[81] Shinar S, Many A, Maslovitz S. Questioning the role of pituitary oxytocin in parturition: spontaneous onset of labor in women with panhypopituitarism-a case series. Eur J Obstet Gynecol Reprod Biol 2016; 197: 83-85

[82] Rohayem J, Sinthofen N, Nieschlag E et al. Causes of hypogonadotropic hypogonadism predict response to gonadotropin substitution in adults. Andrology 2016; 4: 87-94

[83] Liu PY, Baker HW, Jayadev V et al. Induction of spermatogenesis and fertility during gonadotropin treatment of gonadotropin-deficient infertile men: predictors of fertility outcome. J Clin Endocrinol Metab 2009; 94: 801-808

[84] Carone D, Caropreso C, Vitti A et al. Efficacy of different gonadotropin combinations to support ovulation induction in WHO type I anovulation infertility: clinical evidences of human recombinant FSH/human recombinant $\mathrm{LH}$ in a 2:1 ratio and highly purified human menopausal gonadotropin stimulation protocols. J Endocrinol Invest 2012; 35: 9961002

[85] [Anonym]. Recombinant human luteinizing hormone (LH) to support recombinant human follicle-stimulating hormone (FSH)-induced follicular development in LH- and FSH-deficient anovulatory women: a dose-finding study. The European Recombinant Human LH Study Group. J Clin Endocrinol Metab 1998; 83: 1507-1514

[86] Milardi D, Giampietro A, Baldelli R et al. Fertility and hypopituitarism. J Endocrinol Invest 2008; 31: 71-74

[87] Drakopoulos P, Pluchino N, Bischof P et al. Effect of Growth Hormone on Endometrial Thickness and Fertility Outcome in the Treatment of Women with Panhypopituitarism: A Case Report. J Reprod Med 2016; 61: 7882

[88] Zitzmann M, Behre HM, Kliesch S. Gonadotropin treatment in male infertility. J Reproduktionsmed Endokrinol 2013; 10 (Sonderheft 1): 23-28

[89] Zitzmann M, Nieschlag E. Hormone substitution in male hypogonadism. Mol Cell Endocrinol 2000; 161: 73-88 